\title{
The Viewpoints of Last-Year Dentistry Students of Shahid Beheshti University on the Application of Lasers as an Independent Credit in the Education of General Dentistry
}

\author{
Masoumeh Mehdipour', Hamed Mortazavi', Ayla Bahramian², Niloofar Haghighi Enayat ${ }^{3}$, Saranaz Azari- \\ Marhabi $^{*}$ \\ ${ }^{1}$ Shahid Beheshti University of Medical Sciences, Tehran, Iran \\ ${ }^{2}$ Tabriz University of Medical Sciences, Tabriz, Iran \\ ${ }^{3}$ Dentist \\ ${ }^{4}$ Laser Application in Medical Sciences Research Center, Shahid Beheshti University of Medical Sciences, Tehran, Iran
}

\section{*Correspondence to Saranaz Azari-Marhabi Address: Laser Application in Medical Sciences Research Center, Shohada Tajrish Hospital Tajrish Square, Tajrish Street, Tehran, Iran. \\ Tel: +98-912-2172508; Fax: +98-21-22749221 Email: dr.s.azari@sbmu.ac.ir}

Published online March 15 2020

\begin{abstract}
Introduction: Enhancing students' pragmatic skills as an enabling means brings about changes in their curriculum, which should be reconciled with the students' educational needs. Thus, this study seeks to examine the viewpoints of last-year dentistry students on the need for the instruction of laser application as an independent credit in the general dentistry curriculum. The findings of this study can help determine the educational priorities of students while providing and compiling their curriculum.

Methods: This descriptive study was done on 91 last-year dentistry students of Shahid Beheshti University in a full census manner. The data collection tool was a fieldwork questionnaire, the validity and reliability of which were evaluated. To report the findings, frequency distribution, frequency percentage, and average tableaux were utilized.

Results: Amongst the 91 participants, regarding the average figures of value assignment from 1 to 10 to respond to questions, the highest value was assigned to learning the side effects of lasers $(7.99 \pm 0.01)$ and the lowest value was assigned to learning about the history of lasers and light physics $(4.53 \pm 0.47)$.

Conclusion: The findings indicate that students have a positive attitude toward the incorporation of an independent laser credit in their curriculum and thus the necessity of incorporating this credit in their curriculum can be posed.

Keywords: Laser; Dentistry; Curriculum; Dentistry student.
\end{abstract}

\section{Introduction}

Enabling dentistry students to give appropriate services to patients can be considered the most important option in their practical and professional skills. ${ }^{1}$ The development of new technologies and the enhancement of knowledge in recent years have led to devising special therapeutic methods, one of which is the use of lasers. In contemporary dentistry, the use of lasers as a new type of technology has affected many therapeutic schemes. It seems that the educational system ought to take up the instruction of the scientific principles of new technologies in order to be able to cope with manifold therapeutic needs as an educational innovation. Undoubtedly, very adroit and dedicated to preserving health and preventing diseases among people, dentists are trained along this path. ${ }^{2}$
Lasers are utilized extensively in various dentistry fields. The use of lasers in dentistry has a long history.

Yamamoto et al. revealed that researchers used the ruby laser in root canal treatment in 1971. Treating increased sensitivity of pulp, diagnosing pulp defects, pulp capping, and disinfecting the root canal in endodontics can be named as a few of its functions. ${ }^{3}$

In the 1990s, different types of lasers were used in treating soft-tissue lesions. The clinical applications of lasers in removing inflammatory lesions of the gingiva and also gingival pigmentation are examples of such treatments. $^{4}$

The usability of lasers in removing tooth decay, reducing recrudescent decay, strengthening restorations, and bleaching teeth in cosmetic dentistry has been

Please cite this article as follows: Mehdipour M, Mortazavi H, Bahramian A, Haghighi Enayat N, Azari-Marhabi S. The viewpoints of last-year dentistry students of Shahid Beheshti University on the application of lasers as an independent credit in the education of general dentistry. J Lasers Med Sci. 2020;11(2):193-196. doi:10.34172/jlms.2020.32. 
proven. Healing lesions with a minimum scar, reducing the time of operation, and reducing bleeding, swelling and painfulness after an operation are other uses of lasers in surgery. Lasers have also been utilized in the diagnosis of germs and bacteria, the extermination of bacteria, and treating peri-implantitis. ${ }^{5,6}$

In a study by Nkenke et al, it was shown that the amount of medical information doubles every seven years and thus the educational system should also provide the educators and learners increasingly with the new technology and information. University can be the best place to present appropriate training methodologies. ${ }^{7}$

One of the ways to revise the educational system is to survey students' feedback, as they are the best group that can provide feedback on the curriculum. ${ }^{8}$ Thus, this study has been conducted on last year General Dentistry students with the aim of incorporating an independent laser credit in the curriculum with the vision that reflecting its conclusions could help educational legislators with modification of dental paramedics curriculum.

\section{Methods}

This descriptive-sectional study was conducted in 2018 on 91 last-year general dentistry students of Shahid Beheshti University in a census form. Questionnaires were provided and distributed among the students in a field-study and face-to-face manner and then were collected after completion. General, undergraduate dentistry students in the last year of their course were included in the study, and the students who did not approve to complete the questionnaire or gave incomplete replies were excluded.

The questionnaire included 13 questions which were divided into three parts. In the first part, there were questions concerning the instruction of lasers as an independent credit, history of laser and light physics, application of different types of lasers in dentistry, mechanism of action of various types of lasers, and different applications of lasers in dentistry; the second part included questions regarding the application of lasers in hard tissue surgery, removing soft-tissue deformities of the oral cavity, restorative dentistry, periodontal treatments, endodontics, and the management of oral and dental pains; the third part involved questions about the advantages and disadvantages of using lasers. It is worth noting that the questions were not specifically designed, but enough for general dentistry students' knowledge about the application of lasers. Thus, a limited number of applications were considered.

In order to determine the importance and value of each response, they were given a value of between 1 and 10; 1 indicated the least and 10 indicated the utmost importance of incorporating each item.

To investigate the validity index of the content, the Waltz and Basel validity index was used. ${ }^{9}$ To this end, the questionnaire was given to experts to determine the relevance, simplicity, and clarity of each statement in the questionnaire based on the Waltz and Basel validity index. As a result, the three criteria of simplicity, relevance and clarity in a four-part Likert scale for each item were established. For example, for the relevance criterion, the following were applied: item 1 is not relevant, item 2 is rather relevant, item 3 is relevant, and item 4 is completely relevant. The point of validity index for each statement was calculated by dividing the number of experts who agreed with items 3 and 4 by the total number of experts.

In order to confirm the reliability, questionnaires were distributed among 15 students with a two-week interval and the reliability of the questions was confirmed so that each question having an intra-class correlation of 0.5 and above enjoyed reliability.

The figures derived from reviewing the validity and reliability are shown in Table 1.

The results were analyzed in the framework of descriptive statistics using SPSS-21 software, and to present the results, frequency distribution, frequency percentage, and average tables were used.

\section{Results}

Ninety-one (55 females and 36 males) out of 102 respondents completed the questionnaires. Regarding

Table 1. Figures Derived From Reviewing Validity and Reliability

\begin{tabular}{|c|c|c|c|c|c|}
\hline & CVR & Relevance & Simplicity & Clarity & ICC \\
\hline Laser as an independent credit & 0.75 & 0.87 & 0.75 & 0.87 & 0.874 \\
\hline History of laser and light physics & 1 & 1 & 0.62 & 0.87 & 0.866 \\
\hline Application of different types of lasers in dentistry & 0.75 & 1 & 0.75 & 1 & 0.911 \\
\hline Mechanism of action of various types of lasers & 0.75 & 1 & 0.62 & 0.87 & 0.668 \\
\hline Different applications of lasers in dentistry & 0.75 & 0.87 & 0.62 & 0.75 & 0.615 \\
\hline Hard tissue surgeries using lasers & 0.75 & 0.75 & 0.75 & 0.75 & 0.786 \\
\hline Removing soft tissue defects using lasers & 0.75 & 0.75 & 0.75 & 0.87 & 0.701 \\
\hline Restorative dentistry using lasers & 0.75 & 0.75 & 0.75 & 0.75 & 0.843 \\
\hline Periodontal treatment using lasers & 0.75 & 0.87 & 0.75 & 0.87 & 0.873 \\
\hline Endodontic treatment using lasers & 0.75 & 0.87 & 0.75 & 0.87 & 0.873 \\
\hline Management of dental and oral pain using lasers & 0.75 & 0.87 & 0.75 & 0.75 & 0.728 \\
\hline Advantages of using lasers & 1 & 1 & 0.75 & 0.75 & 0.846 \\
\hline Side effects of using lasers & 0.75 & 1 & 0.75 & 0.75 & 0.610 \\
\hline
\end{tabular}

CVR, Content validity ratio; ICC, intra-class correlation. 
the ranking of viewpoints from 1 to 10 , the mean figures of valuation and the degree of standard deviation are reported in Table 2. All the questions, except question no. 2 , possessed a value of above 6 , which denotes complete agreement.

\section{Discussion}

An educational curriculum can be successful when it is effective in training efficient and skilled students. Thus, knowledge of students' opinions as a means of reevaluating the curriculum in retrospect can be noticed. ${ }^{1,10}$

Ours was the first study done at a dentistry department about needs analysis of teaching the application of lasers in general dentistry on the students who were graduating and had passed all the theoretical and practical credits of their course.

In 2014, a study was conducted in Malek Soud University by Al-Jobair to evaluate the educational and knowledge level of last-year dentistry students on laser application. In that study, questionnaires were given to 94 students and it was concluded that $91.5 \%$ of students did not have enough information and knowledge about laser application and had not enjoyed enough instruction during their course. $83 \%$ of students demanded the necessary instruction of a laser credit. ${ }^{10}$ Similarly, all the students in the present study insisted on the necessity of its incorporation in the general course.

Bordea et al conducted a study in 2016 to evaluate the knowledge of 219 dentistry students. In that study, which was done by means of the distribution of a questionnaire similar to the one used in the study conducted by AlJobair, the same questions as the ones in the present study, including various types of lasers, instruction of basic principles of lasers, the side-effects of applying lasers were asked. Similar results to the findings of the present study were reported about the fields of surgery and endodontics as the ones needing instruction. In Bordea and colleagues' study, many of the questions and the target society were similar to the present research and thus the findings were, to a great extent, reported as corresponding to the ones in the present research, with the only difference in the number of studied cases in that study. ${ }^{11}$

It should be pointed out that the absence of some students who were at the stage of finishing the curriculum and a paucity of studies to compare their findings with those of this study were the limitations of the present study.

It is suggested that this study be conducted on general dentistry courses at all levels and the students' feedback at each level be compared. Then it can be done in several dentistry departments in a comparative fashion.

\section{Conclusion}

Regarding the expansion of the concept of health and sanitation in humans' life and the dentists' role in enhancing public services and in order to update
Table 2. Average Need of Last-Year Dentistry Students for Laser Headings

\begin{tabular}{lc}
\hline Laser Credit Heading & Mean \pm SD \\
\hline Laser as an independent credit & $6.97 \pm 2.385$ \\
History of laser and light physics & $4.53 \pm 0.47$ \\
Application of Different Types of Lasers in Dentistry & $7.48 \pm 2.685$ \\
Mechanism of action of lasers & $6.77 \pm 2.737$ \\
Different applications of lasers in dentistry & $7.66 \pm 2.736$ \\
Hard tissue surgeries using lasers & $7.59 \pm 2.736$ \\
Removing soft-tissue defects using lasers & $7.29 \pm 2.818$ \\
\hline Restorative dentistry using lasers & $7.05 \pm 2.888$ \\
\hline Periodontal surgery using lasers & $7.73 \pm 2.556$ \\
Endodontic treatments using lasers & $6.87 \pm 3.070$ \\
\hline Management of oral and dental pain using lasers & $7.56 \pm 2.482$ \\
\hline Advantages of using lasers & $7.96 \pm 2.319$ \\
\hline Side effects of using lasers & $7.99 \pm 0.01$ \\
\hline SD, standard deviation.
\end{tabular}

SD, standard deviation.

the curriculum, incorporating the instruction of the application of lasers and allocating an independent credit to it for general dentistry students in a systematic fashion seem helpful in the continuous enhancement of instruction.

\section{Ethical Considerations}

All students signed the informed consent to take part in the survey.

\section{Conflict of Interests}

The authors declare no conflict of interest.

\section{Acknowledgments}

We would like to extend our gratitude to all the students who took part in this survey.

\section{References}

1. Mokhtari M, Foroozanfar A, Farazi F. Assessment of final year dental students view of science education in dental implants. J Mashhad Dent Sch. 2012;36(2):157-64. [Persian].

2. Ricketts DNJ, Pitts NB. Novel operative treatment options. Monogr Oral Sci. 2009;21:174-187. doi: 10.1159/000224222.

3. Yamamoto H, Sato K. Prevention of dental caries by acoustooptically Q-switched Nd: YAG laser irradiation. J Dent Res. 1980;59(2):137. doi: 10.1177/00220345800590020801.

4. Whitters CJ, Hall A, Creanor SL, Moseley H, Gilmour WH, Strang R, et al. A clinical study of pulsed Nd: YAG laser induced pulpal analgesia. J Dent. 1995;23(3):145-50. doi: 10.1016/0300-5712(95)93571-i.

5. Crespi R, Romanos GE, Barone A, Sculean A, Covani U. Er: YAG laser in defocused mode for scaling of periodontally involved root surfaces: An in vitro pilot study. J Periodontol. 2005;76(5):686-90. doi: 10.1902/jop.2005.76.5.686.

6. Verma SK, Maheshwari S, Singh RK, Chaudhari PK. Laser in dentistry: An innovative tool in modern dental 
practice. Natl J Maxillofac Surg. 2012;3(2):124-32. doi: 10.4103/0975-5950.111342.

7. Nkenke E, Vairaktaris E, Bauersachs A, Eitner S, Budach A, Knipfer C, et al. Acceptance of technology-enhanced learning for a theoretical radiological science course: a randomized controlled trial. BMC Med Educ. 2012;12:18. doi: 10.1186/1472-6920-12-18.

8. Fazel A, Jafari A, Khami M, Seddighpour L, Kharrazifard $\mathrm{M}$, Nassibi $\mathrm{M}$, et al. Dental curriculum revision in Iran: Dentists' perspective on achievement of essential competencies through national curriculum. Iran J Public Health. 2013;42(Suppl 1):129-33.
9. Polit DF, Beck CT. The content validity index: are you sure you know what's being reported? Critique and recommendations. Res Nurs Health. 2006;29(5):489-97. doi: 10.1002/nur.20147.

10. Al-Jobair A. Dental laser education and knowledge among final year dental students at King Saud University in Riyadh, Saudi Arabia. Saudi J Dent Res. 2014;5(2):98-103. doi: 10.1016/j.sjdr.2013.11.001.

11. Bordea R, Lucaciu O, Câmpian RS. Student's knowledge and opinion regarding the need of implementation of Lasers in Dental Faculty curriculum. HVM Bioflux. 2016;8(4):157-160. 